\title{
A Prospective Cohort Study of Muscular and Performance Fitness and Incident Glaucoma: The Niigata Wellness Study
}

\author{
Ryoko Kawakami, Yuko Gando, Kiminori Kato, Susumu S. Sawada, Haruki Momma, Motohiko Miyachi, \\ I-Min Lee, Steven N. Blair, Minoru Tashiro, Chika Horikawa, Yasuhiro Matsubayashi, Takaho Yamada, \\ Kazuya Fujihara, and Hirohito Sone
}

\begin{abstract}
Background: To examine the association between muscular and performance fitness (MPF) and the incidence of glaucoma. Methods: A total of 27,051 glaucoma-free participants aged 20-87 years underwent physical fitness tests between April 2001 and March 2002. The MPF index was calculated using an age- and sex-specific summed $z$-score from grip strength, vertical jump, single-leg balance, forward bending, and whole-body reaction time. The participants were divided into quartiles according to the MPF index and each physical fitness test. Participants were followed up for the development of glaucoma, which was defined based on physician-diagnosed glaucoma at an annual health examination between April 2002 and March 2008. Hazard ratios for the incidence of glaucoma were estimated using Cox proportional hazards models. Results: During follow-up, 303 participants developed glaucoma. Compared with the lowest MPF index group, hazard ratio (95\% confidence interval) of developing glaucoma was $0.64(0.46-0.89)$ for the highest MPF index group $(P$ for trend $=.001)$. Vertical jump and whole-body reaction time were associated with incident glaucoma $(P$ for trend $=.01$ and $<.001$, respectively). There were no associations between the other physical fitness tests and the incidence of glaucoma. Conclusion: Higher MPF is associated with lower incidence of glaucoma.
\end{abstract}

Keywords: epidemiology, physical fitness, physical performance, public health, strength

The prevalence of glaucoma has been increasing worldwide. The number of individuals with glaucoma worldwide has been predicted to increase from 64.3 million in 2013 to 111.8 million in $2040 .{ }^{1}$ Glaucoma is a serious disease and a leading cause of irreversible blindness. ${ }^{2}$ The incidence of glaucoma is associated with modifiable lifestyle factors as well as age and genetic factors and has

(C) 2020 The Authors. Published by Human Kinetics, Inc. This is an Open Access article distributed under the terms of the Creative Commons Attribution-NonCommercial 4.0 International License, CC BY-NC 4.0, which permits the copy and redistribution in any medium or format, provided it is not used for commercial purposes, the original work is properly cited, the new use includes a link to the license, and any changes are indicated. See http://creativecommons.org/licenses/bync/4.0. This license does not cover any third-party material that may appear with permission in the article. For commercial use, permission should be requested from Human Kinetics, Inc., through the Copyright Clearance Center (http://www. copyright.com).

Kawakami and Sawada are with the Faculty of Sport Sciences, Waseda University, Saitama, Japan. Kawakami, Gando, and Miyachi are with the Department of Physical Activity Research, National Institutes of Biomedical Innovation, Health and Nutrition, Tokyo, Japan. Kawakami, Gando, Momma, Horikawa, Matsubayashi, Yamada, Fujihara, and Sone are with the Department of Hematology, Endocrinology and Metabolism, Niigata University Faculty of Medicine, Niigata, Japan. Kato is with the Department of Prevention of Noncommunicable Diseases and Promotion of Health Checkup, Niigata University Graduate School of Medical and Dental Sciences, Niigata, Japan. Momma is with the Department of Medicine and Science in Sports and Exercise, Tohoku University Graduate School of Medicine, Sendai, Japan. Lee is with the Division of Preventive Medicine, Brigham and Women's Hospital, Harvard Medical School, Boston, MA, USA; and with the Department of Epidemiology, Harvard T.H. Chan School of Public Health, Boston, MA, USA. Blair is with the Arnold School of Public Health, University of South Carolina, Columbia, SC, USA. Tashiro is with the Niigata Association of Occupational Health, Niigata, Japan. Horikawa is also with the Department of Health and Nutrition, University of Niigata Prefecture Faculty of Human Life Studies, Niigata, Japan. Sone (sone@med.niigata-u.ac.jp) is corresponding author. been reported to be preventable through appropriate physical activity. ${ }^{3-5}$ Thus, finding useful physical fitness-related factors associated with prevention of glaucoma is an important public health issue.

Previous prospective cohort studies have demonstrated that high cardiorespiratory fitness is associated with a lower risk of developing glaucoma. ${ }^{3,6}$ Although cardiorespiratory fitness is an element of physical fitness that is reportedly associated with various health outcomes, ${ }^{7}$ physical fitness also includes other elements, such as muscle strength, power, balance, flexibility, and reaction time ${ }^{8}$ However, to our knowledge, relationships between physical fitness elements other than cardiorespiratory fitness and glaucoma development have not been examined in previous epidemiologic studies. Therefore, this prospective cohort study aimed to examine the associations of muscular and performance fitness (MPF) using 5 different tests (grip strength, vertical jump, single-leg balance, forward bending, and whole-body reaction time) that evaluate various physical fitness elements in an objective manner and the incidence of glaucoma.

\section{Methods}

\section{Participants}

Our prospective cohort study included Japanese individuals who underwent annual health examinations by the Niigata Association of Occupational Health in Niigata, Japan, as described previously. ${ }^{9}$ This longitudinal study included 55,347 participants who underwent initial examinations between April 2001 and March 2002. Of 55,347 participants, 35,262 participants underwent all 5 physical fitness tests at baseline. We excluded 1380 participants who reported a history of glaucoma $(n=169)$, cancer $(n=365)$, heart disease $(n=697)$, or stroke $(n=192)$ at baseline examination. Some excluded participants met two or more of these conditions. Among the remaining 33,882 participants, 170 with missing covariate 
variables and 6661 with incomplete follow-up were excluded. Finally, 27,051 participants (18,472 men and 8579 women) aged 20-87 years were included in the present analysis.

This study was approved by the Ethics Committees of the National Institutes of Biomedical Innovation, Health and Nutrition and the School of Medicine, Faculty of Medicine, Niigata University. Written informed consent was obtained from all participants. This study was conducted in accordance with the Declaration of Helsinki and the Japanese Ethical Guidelines.

\section{Physical Fitness Tests}

The details of the physical fitness tests were described previously. ${ }^{10}$ Muscle strength was measured using a grip strength dynamometer (T.K.K. 5401; Takei Scientific Instruments Co, Ltd, Niigata, Japan). Grip strength (kg) was measured once for each hand, and the higher value was used. Muscle power was assessed using a vertical jumpmeasuring instrument (T.K.K. 5414; Takei Scientific Instruments Co). The jump height $(\mathrm{cm})$ was assessed based on the equation of jumping time and distance. Each individual performed 2 trials, and the best performance was used. Static balance was assessed by measuring the duration (s) of single-leg balance with eyes closed. Participants were asked to maintain a standing position with their hands placed on hips for up to 240 seconds. Trunk flexibility was measured using a digital flexibility testing device (T.K.K. 5403; Takei Scientific Instruments Co). Participants were asked to stand on a measuring bench with their toes even with the front edge of the bench and then asked to bend over and reach down as far as possible while keeping the knees locked. Performance was scored as the distance (cm) reached by the middle fingers. Whole-body reaction time was measured using a pressure-sensing mat (T.K.K. 5408; Takei Scientific Instruments Co). Participants were asked to stand on the mat and jump upright as quickly as possible in response to a red light signal. The time (ms) between the flashing and disappearance of foot pressure from the mat was measured. Participants underwent 3 trials, and the average of the 3 trials was calculated.

The MPF index was calculated using an age- and sex-specific summed $z$-score from grip strength, vertical jump, single-leg balance with eyes closed, forward bending, and whole-body reaction time. The $z$-score of the whole-body reaction time was converted to a reverse score. Composite $z$-scores obtained from different physical fitness tests have been used in previous studies. ${ }^{11-13}$

\section{Definition of Incident Glaucoma}

Participants reported physician-diagnosed glaucoma on their medical history questionnaires. We determined the month that participants developed glaucoma based on their reports at the annual health examination between April 2002 and March 2008. This definition was the same as that used in the previous studies. 3,6

\section{Covariate Assessments}

Height, weight, and blood pressure were measured at baseline health examinations. Body mass index (BMI) was calculated $\left(\mathrm{kg} / \mathrm{m}^{2}\right)$. Blood samples collected after an overnight fast were measured for triglyceride, low-density lipoprotein and high-density lipoprotein cholesterol, blood glucose, and hemoglobin A1c levels. Corrected visual acuity in each eye was assessed with a Landolt broken ring chart at a 5-m distance using an automatic visual analyzer (CA-1000, Tomey Corp, Nagoya, Japan). For statistical analyses, the decimal visual acuity values were converted to the logarithm of the minimum angle of resolution units in the better eye. Self-reported questionnaires were used to assess cigarette smoking, alcohol drinking, and history of physician-diagnosed hypertension, dyslipidemia, and diabetes.

\section{Statistical Analysis}

For participant characteristics, continuous variables were expressed as medians (interquartile range) and categorical variables were expressed as percentages. Participants were classified into quartiles according to the MPF index and age- and sex-specific physical fitness test (in 5-y increments). Cox proportional hazards regression analyses were performed to investigate the relationship between physical fitness and glaucoma incidence. We then calculated ageand sex-adjusted hazard ratios (HRs) and 95\% confidence intervals according to the quartiles of physical fitness (model 1). In multivariable-adjusted models (model 2), we calculated the HRs adjusted for age (y, continuous); sex (men or women); BMI ( $\mathrm{kg} / \mathrm{m}^{2}$, continuous); cigarette smoking (never smoker, former smoker, or current smoker); alcohol drinking (none, 1-2 d/wk, 3-6 d/wk, or every day); hypertension (defined as systolic blood pressure $\geq 140 \mathrm{~mm} \mathrm{Hg}$, diastolic blood pressure $\geq 90 \mathrm{~mm} \mathrm{Hg}$, or self-reported physician-diagnosed hypertension [yes or no]); dyslipidemia (defined as triglycerides $\geq 150 \mathrm{mg} / \mathrm{dL}$, low-density lipoprotein-cholesterol $\geq 140 \mathrm{mg} / \mathrm{dL}$, high-density lipoprotein-cholesterol $<40 \mathrm{mg} / \mathrm{dL}$, or self-reported physician-diagnosed dyslipidemia [yes or no]); diabetes (defined as blood glucose $\geq$ $126 \mathrm{mg} / \mathrm{dL}$, hemoglobin A1c $\geq 6.5 \%$, or self-reported physiciandiagnosed diabetes [yes or no]); better-corrected visual acuity (logarithm of the minimum angle of resolution, continuous); and visual correction (yes or no). Moreover, in model 3, other physical fitness was adjusted in addition to model 2 covariates. These covariates were chosen based on their associations with glaucoma reported previously. ${ }^{3}$ In addition, myopia is one of the risk factors of glaucoma. ${ }^{14}$ Therefore, we further adjusted for better-corrected visual acuity and visual correction, which might also be associated with whole-body reaction time assessed by vision.

Sensitivity analyses were performed to minimize the possibility of reverse causation in which the participants who developed glaucoma during the initial 2-y follow-up were excluded. Similar sensitivity analyses were performed in previous studies. ${ }^{15-17}$ Additionally, we imputed missing exposure and covariate data using a multiple imputation by chained equations with 10 complete data sets. All variables described in model 3 were used to impute missing values. To examine the interaction of age $(<50$ and $\geq 50 \mathrm{y})$, sex (men and women), or BMI ( $<25$ and $\geq 25 \mathrm{~kg} / \mathrm{m}^{2}$ ) and each physical fitness test with incident glaucoma, the interaction terms were entered into the multivariable Cox proportional hazards regression models.

All statistical analyses were performed using SPSS Statistics (version 25; IBM Corp, Armonk, NY). Statistical significance was set at $P<.05$ in two-tailed tests.

\section{Results}

The median age of participants at baseline was $50 \mathrm{y}$ (interquartile range, 44-56 y). The median follow-up among all the participants was 5.8 y (total follow-up, 130,792 person-years), during which glaucoma developed in 303 participants $(1.1 \%)$. Table 1 shows the baseline characteristics of 27,051 participants by MPF index level. In the highest MPF index group (quartile 4, highest fitness group), there were fewer smokers, and these participants tended to have a lower BMI and lower prevalence of hypertension, dyslipidemia, and diabetes. In the participants who developed glaucoma, there was a higher prevalence of hypertension, dyslipidemia, and diabetes, and the MPF index level was low (Supplementary Table S1 [available online]). 
Table 1 Baseline Characteristics of Study Participants According to Muscular and Performance Fitness Index Levels $^{\mathrm{a}}$

\begin{tabular}{|c|c|c|c|c|c|}
\hline \multirow[b]{2}{*}{ Characteristics } & \multirow[b]{2}{*}{ Overall } & \multicolumn{4}{|c|}{ Muscular and performance fitness index } \\
\hline & & $\begin{array}{c}\text { Quartile } 1 \text { (lowest } \\
\text { fitness) }\end{array}$ & Quartile 2 & Quartile 3 & $\begin{array}{c}\text { Quartile } 4 \text { (highest } \\
\text { fitness) }\end{array}$ \\
\hline No. of participants & 27,051 & 6762 & 6763 & 6763 & 6763 \\
\hline Age, y & $50(44-56)$ & $50(44-56)$ & $50(44-56)$ & $50(44-56)$ & $50(44-56)$ \\
\hline Men, $\%$ & 68.3 & 68.0 & 68.9 & 68.5 & 67.7 \\
\hline Body mass index, $\mathrm{kg} / \mathrm{m}^{2}$ & $22.7(20.9-24.6)$ & $22.8(20.8-24.8)$ & $22.7(20.9-24.7)$ & $22.8(20.9-24.6)$ & $22.5(20.8-24.4)$ \\
\hline \multicolumn{6}{|l|}{ Cigarette smoking, $\%$} \\
\hline Never smoker & 45.9 & 43.9 & 43.8 & 46.0 & 49.7 \\
\hline Former smoker & 19.0 & 16.6 & 18.1 & 20.2 & 21.3 \\
\hline Current smoker & 35.1 & 39.5 & 38.1 & 33.8 & 29.0 \\
\hline \multicolumn{6}{|l|}{ Alcohol drinking, $\%$} \\
\hline None & 26.3 & 28.7 & 25.8 & 25.5 & 25.2 \\
\hline $1-2 \mathrm{~d} / \mathrm{wk}$ & 15.6 & 14.2 & 15.5 & 15.2 & 17.6 \\
\hline $3-6 \mathrm{~d} / \mathrm{wk}$ & 23.1 & 21.0 & 22.7 & 23.6 & 25.0 \\
\hline Every day & 35.0 & 36.1 & 36.0 & 35.7 & 32.2 \\
\hline Systolic blood pressure, $\mathrm{mm} \mathrm{Hg}$ & $117(108-128)$ & $118(108-128)$ & $118(109-128)$ & $117(108-128)$ & $117(108-127)$ \\
\hline Diastolic blood pressure, $\mathrm{mm} \mathrm{Hg}$ & $76(68-83)$ & $77(68-83)$ & $76(68-83)$ & $76(68-83)$ & $76(68-83)$ \\
\hline Hypertension, $\%^{\mathrm{b}}$ & 20.4 & 21.9 & 20.1 & 20.8 & 18.9 \\
\hline Triglyceride, $\mathrm{mg} / \mathrm{dL}$ & $96(68-141)$ & $98(69-145)$ & $101(69-146)$ & $96(68-141)$ & $90(64-131)$ \\
\hline LDL-cholesterol, mg/dL & $118(98-139)$ & $118(98-140)$ & $119(99-140)$ & $117(98-139)$ & $117(98-137)$ \\
\hline HDL-cholesterol, mg/dL & $59(50-71)$ & $59(49-70)$ & $59(49-70)$ & $59(50-70)$ & $60(51-72)$ \\
\hline Dyslipidemia, $\%^{\mathrm{c}}$ & 42.4 & 44.3 & 44.3 & 42.3 & 38.5 \\
\hline Blood glucose, mg/dL & $94(88-101)$ & $94(89-102)$ & $94(88-101)$ & $94(88-101)$ & $93(88-100)$ \\
\hline $\mathrm{HbA} 1 \mathrm{c}, \%$ & $5.1(4.9-5.5)$ & $5.2(4.9-5.5)$ & $5.2(4.9-5.5)$ & $5.1(4.9-5.5)$ & $5.1(4.9-5.5)$ \\
\hline Diabetes, $\%^{\mathrm{d}}$ & 5.7 & 7.5 & 5.8 & 5.0 & 4.4 \\
\hline Corrected visual acuity, $\log$ MAR & $\begin{array}{c}0.00(-0.08 \text { to } \\
0.10)\end{array}$ & $0.00(-0.08$ to 0.15$)$ & $\begin{array}{c}0.00(-0.08 \text { to } \\
0.10)\end{array}$ & $\begin{array}{c}0.00(-0.18 \text { to } \\
0.10)\end{array}$ & $-0.08(-0.18$ to 0.10$)$ \\
\hline Visual correction, $\%$ & 35.6 & 34.4 & 35.0 & 36.1 & 37.0 \\
\hline Grip strength, kg & $40(30-46)$ & $36(26-42)$ & $39(29-45)$ & $41(31-47)$ & $44(33-50)$ \\
\hline Vertical jump, cm & $41(34-47)$ & $36(30-42)$ & $40(33-46)$ & $42(35-48)$ & $45(38-52)$ \\
\hline Single-leg balance, s & $33(15-64)$ & $18(9-35)$ & $26(13-50)$ & $37(18-65)$ & $64(34-112)$ \\
\hline Forward bending, $\mathrm{cm}$ & $8(2-13)$ & $2(-4$ to 7$)$ & $6(2$ to 11$)$ & $9(4-14)$ & $13(8-17)$ \\
\hline Whole-body reaction time, $\mathrm{ms}$ & $351(324-384)$ & $387(355-427)$ & $357(333-386)$ & $342(320-368)$ & $326(305-350)$ \\
\hline $\begin{array}{l}\text { Muscular and performance fitness } \\
\text { index }^{\mathrm{e}}\end{array}$ & $\begin{array}{c}-0.01(-1.84 \text { to } \\
1.84)\end{array}$ & $-3.17(-4.28$ to -2.42$)$ & $\begin{array}{c}-0.87(-1.34 \text { to } \\
-0.44)\end{array}$ & $\begin{array}{c}0.84(0.40 \text { to } \\
1.32)\end{array}$ & $3.18(2.41$ to 4.30$)$ \\
\hline
\end{tabular}

Abbreviations: HbA1c, hemoglobin A1c; HDL, high-density lipoprotein; LDL, low-density lipoprotein; logMAR, logarithm of the minimum angle of resolution.

${ }^{\mathrm{a}}$ Data are expressed as median (interquartile range) or percentages of participants at baseline. ${ }^{\mathrm{b}}$ Defined as systolic blood pressure $\geq 140 \mathrm{~mm} \mathrm{Hg}$, diastolic blood pressure $\geq 90 \mathrm{~mm} \mathrm{Hg}$, or physician diagnosis. ${ }^{c}$ Defined as triglyceride $\geq 150 \mathrm{mg} / \mathrm{dL}$, LDL-cholesterol $\geq 140 \mathrm{mg} / \mathrm{dL}$, HDL-cholesterol $<40 \mathrm{mg} / \mathrm{dL}$, or physician diagnosis. ${ }^{\mathrm{d}}$ Defined as fasting blood glucose $\geq 126 \mathrm{mg} / \mathrm{dL}, \mathrm{HbA} 1 \mathrm{c} \geq 6.5 \%$, or physician diagnosis. ${ }^{\mathrm{e}} \mathrm{Sum}$ of $z$-score from grip strength, vertical jump, single-leg balance with eyes closed, forward bending, and whole-body reaction time.

Table 2 shows the multivariable-adjusted HRs of glaucoma incidence by potential risk factors. There was a significant inverse association between MPF index and incident glaucoma $(P$ for trend $=$ .001 ). Compared with the lowest MPF index group (quartile 1), multivariable-adjusted HRs of glaucoma incidence were 1.02 (95\% confidence interval, 0.76-1.37) for quartile 2, $0.69(0.50-0.96)$ for quartile 3 , and 0.64 (0.46-0.89) for quartile 4. In addition, older age, former smokers, hypertension, and visual correction significantly increased the risk of incident glaucoma.

Table 3 shows the age- and sex-adjusted and multivariableadjusted HRs of glaucoma incidence by each physical fitness test.
Vertical jump and whole-body reaction time were significantly inversely associated with incident glaucoma after multivariable adjustment for potential risk factors (model $3 ; P$ for trend $=.01$ and $<.001$, respectively). Grip strength, single-leg balance, and forward bending were not associated with incident glaucoma.

All sensitivity analyses showed similar results after excluding participants who developed glaucoma during the initial 2-year follow-up (Supplementary Table S2 [available online]) and after multiple imputation of missing values (Supplementary Table S3 [available online]). There were no interactions of age, sex, or BMI and each physical fitness test with incident glaucoma, except for 
Table 2 Hazard Ratios of Glaucoma Incidence According to Potential Risk Factors ${ }^{a}$

\begin{tabular}{|c|c|c|c|c|}
\hline Variables & No. of participants & No. of cases & Hazard ratios & (95\% confidence intervals) \\
\hline Age, $y$ & 27,051 & 303 & 1.05 & $(1.03-1.06)$ \\
\hline \multicolumn{5}{|l|}{ Sex } \\
\hline Men & 18,472 & 202 & 1.00 & (reference) \\
\hline Women & 8579 & 101 & 1.39 & $(0.98-1.96)$ \\
\hline Body mass index, $\mathrm{kg} / \mathrm{m}^{2}$ & 27,051 & 303 & 1.02 & $(0.98-1.06)$ \\
\hline \multicolumn{5}{|l|}{ Cigarette smoking } \\
\hline Never smoker & 12,407 & 139 & 1.00 & (reference) \\
\hline Former smoker & 5152 & 81 & 1.49 & $(1.07-2.08)$ \\
\hline \multirow[t]{2}{*}{ Current smoker } & 9492 & 83 & 0.99 & $(0.71-1.38)$ \\
\hline & & & \multicolumn{2}{|c|}{$P$ for trend $=.81$} \\
\hline \multicolumn{5}{|l|}{ Alcohol drinking } \\
\hline None & 7114 & 85 & 1.00 & (reference) \\
\hline $1-2 \mathrm{~d} / \mathrm{wk}$ & 4231 & 49 & 1.08 & $(0.75-1.56)$ \\
\hline $3-6 \mathrm{~d} / \mathrm{wk}$ & 6239 & 63 & 0.93 & $(0.65-1.34)$ \\
\hline \multirow[t]{2}{*}{ Every day } & 9467 & 106 & 1.02 & $(0.72-1.44)$ \\
\hline & & & \multicolumn{2}{|c|}{$P$ for trend $=.96$} \\
\hline \multicolumn{5}{|l|}{ Hypertension } \\
\hline No & 21,522 & 214 & 1.00 & (reference) \\
\hline Yes & 5529 & 89 & 1.36 & $(1.04-1.77)$ \\
\hline \multicolumn{5}{|l|}{ Dyslipidemia } \\
\hline No & 15,588 & 161 & 1.00 & (reference) \\
\hline Yes & 11,463 & 142 & 1.07 & $(0.85-1.36)$ \\
\hline \multicolumn{5}{|l|}{ Diabetes } \\
\hline No & 25,522 & 277 & 1.00 & (reference) \\
\hline Yes & 1529 & 26 & 1.30 & $(0.86-1.95)$ \\
\hline Corrected visual acuity, logMAR & 27,051 & 303 & 1.34 & $(0.74-2.41)$ \\
\hline \multicolumn{5}{|l|}{ Visual correction } \\
\hline No & 17,409 & 167 & 1.00 & (reference) \\
\hline Yes & 9642 & 136 & 1.69 & $(1.34-2.13)$ \\
\hline \multicolumn{5}{|c|}{ Muscular and performance fitness index ${ }^{b}$} \\
\hline Quartile 1 (lowest fitness) & 6762 & 87 & 1.00 & (reference) \\
\hline Quartile 2 & 6763 & 92 & 1.02 & $(0.76-1.37)$ \\
\hline Quartile 3 & 6763 & 64 & 0.69 & $(0.50-0.96)$ \\
\hline \multirow[t]{2}{*}{ Quartile 4 (highest fitness) } & 6763 & 60 & 0.64 & $(0.46-0.89)$ \\
\hline & & & \multicolumn{2}{|c|}{$P$ for trend $=.001$} \\
\hline
\end{tabular}

Abbreviation: logMAR, logarithm of the minimum angle of resolution.

${ }^{a}$ Adjusted for all items in the table. ${ }^{b}$ Sum of $z$-score from grip strength, vertical jump, single-leg balance with eyes closed, forward bending, and whole-body reaction time.

forward bending (data not shown). There was an interaction between sex and forward bending on incident glaucoma ( $P$ for interaction $=.05)$. However, in analysis stratified by sex, there were no associations between forward bending and incident glaucoma in either sex $(P$ for trend $=.11$ in men, $P$ for trend $=.21$ in women $)$.

\section{Discussion}

In this prospective cohort study, we examined the associations of MPF using 5 different tests that evaluate various physical fitness elements in an objective manner and the incidence of glaucoma. Our results indicate that high MPF was associated with a lower risk of developing glaucoma. Moreover, among the various physical fitness elements tested, we found that vertical jump and whole- body reaction time exhibited a significant dose-response relationship with incidence of glaucoma.

In this study, high MPF was confirmed to be associated with a lower risk of developing glaucoma. To our knowledge, the association between cardiorespiratory fitness and incidence of glaucoma has been described in 2 prospective cohort studies. The National Runners' Health Study in which 29,854 male runners were followed for an average of 7.7 years found a negative association between cardiorespiratory fitness assessed through $10-\mathrm{km}$ run performance (speed) and the incidence of glaucoma. ${ }^{6}$ The Aerobics Center Longitudinal Study, which included 9519 middle-aged and older individuals with a mean follow-up of 5.7 years, has shown that participants with a higher level of cardiorespiratory fitness assessed by a maximal treadmill test had a lower risk of developing 
Table 3 Hazard Ratios of Glaucoma Incidence According to Each Physical Fitness Test

\begin{tabular}{|c|c|c|c|c|c|}
\hline Physical fitness & Quartile 1 (lowest fitness) & Quartile 2 & Quartile 3 & Quartile 4 (highest fitness) & $P$ for trend \\
\hline \multicolumn{6}{|l|}{ Grip strength } \\
\hline No. of participants & 7711 & 6700 & 6596 & 6044 & \\
\hline No. of cases & 93 & 66 & 85 & 59 & \\
\hline Model $1^{\mathrm{a}}$ & 1.00 (reference) & $0.81(0.59-1.11)$ & $1.07(0.80-1.43)$ & $0.80(0.57-1.10)$ & .47 \\
\hline Model $2^{\mathrm{b}}$ & 1.00 (reference) & $0.79(0.57-1.08)$ & $1.04(0.78-1.40)$ & $0.76(0.54-1.05)$ & .31 \\
\hline Model $3^{\mathrm{c}}$ & 1.00 (reference) & $0.82(0.60-1.13)$ & $1.11(0.82-1.51)$ & $0.82(0.58-1.16)$ & .65 \\
\hline \multicolumn{6}{|l|}{ Vertical jump } \\
\hline No. of participants & 7591 & 7080 & 6419 & 5961 & \\
\hline No. of cases & 108 & 74 & 72 & 49 & \\
\hline Model $1^{\mathrm{a}}$ & 1.00 (reference) & $0.72(0.53-0.96)$ & $0.80(0.59-1.07)$ & $0.57(0.41-0.80)$ & .003 \\
\hline Model $2^{\mathrm{b}}$ & 1.00 (reference) & $0.71(0.53-0.96)$ & $0.79(0.59-1.07)$ & $0.57(0.40-0.80)$ & .003 \\
\hline Model $3^{c}$ & 1.00 (reference) & $0.73(0.54-0.99)$ & $0.83(0.61-1.13)$ & $0.61(0.42-0.87)$ & .01 \\
\hline \multicolumn{6}{|l|}{ Single-leg balance } \\
\hline No. of participants & 7037 & 6763 & 6601 & 6650 & \\
\hline No. of cases & 85 & 70 & 75 & 73 & \\
\hline Model $1^{\mathrm{a}}$ & 1.00 (reference) & $0.83(0.61-1.15)$ & $0.93(0.68-1.26)$ & $0.88(0.64-1.20)$ & .55 \\
\hline Model $2^{\mathrm{b}}$ & 1.00 (reference) & $0.84(0.61-1.15)$ & $0.93(0.68-1.27)$ & $0.88(0.64-1.21)$ & .58 \\
\hline Model $3^{c}$ & 1.00 (reference) & $0.88(0.64-1.20)$ & $1.00(0.73-1.37)$ & $0.98(0.71-1.36)$ & .90 \\
\hline \multicolumn{6}{|l|}{ Forward bending } \\
\hline No. of participants & 7413 & 7000 & 6555 & 6083 & \\
\hline No. of cases & 77 & 81 & 85 & 60 & \\
\hline Model $1^{\mathrm{a}}$ & 1.00 (reference) & $1.10(0.81-1.51)$ & $1.22(0.90-1.66)$ & $0.91(0.65-1.27)$ & .82 \\
\hline Model $2^{b}$ & 1.00 (reference) & $1.11(0.81-1.52)$ & $1.24(0.91-1.69)$ & $0.95(0.68-1.33)$ & .95 \\
\hline Model $3^{c}$ & 1.00 (reference) & $1.15(0.84-1.58)$ & $1.31(0.96-1.79)$ & $1.03(0.73-1.46)$ & .57 \\
\hline \multicolumn{6}{|c|}{ Whole-body reaction time } \\
\hline No. of participants & 6640 & 6786 & 6730 & 6895 & \\
\hline No. of cases & 98 & 80 & 68 & 57 & \\
\hline Model $1^{\mathrm{a}}$ & 1.00 (reference) & $0.77(0.57-1.03)$ & $0.65(0.48-0.89)$ & $0.51(0.37-0.71)$ & $<.001$ \\
\hline Model $2^{b}$ & 1.00 (reference) & $0.76(0.57-1.02)$ & $0.64(0.47-0.88)$ & $0.51(0.37-0.71)$ & $<.001$ \\
\hline Model $3^{c}$ & 1.00 (reference) & $0.77(0.57-1.03)$ & $0.65(0.48-0.90)$ & $0.52(0.37-0.74)$ & $<.001$ \\
\hline
\end{tabular}

${ }^{\mathrm{a}}$ Model 1: adjusted for age and sex. ${ }^{\mathrm{b}}$ Model 2: adjusted for model 1 covariates plus body mass index, cigarette smoking, alcohol drinking, hypertension, dyslipidemia, diabetes, corrected visual acuity, and visual correction. ${ }^{\mathrm{c}}$ Model 3: adjusted for model 2 covariates plus other physical fitness.

glaucoma. ${ }^{3}$ These findings suggest that glaucoma may be preventable by improving physical fitness with regular exercise.

Physical fitness can be improved by exercise training. The possibility of preventing glaucoma through appropriate exercise has been described in review articles on the effects of exercise on glaucoma. ${ }^{4,5}$ However, the molecular mechanisms controlling the associations between exercise and incidence of glaucoma are not fully understood. Elevated intraocular pressure is a well-known risk factor of developing glaucoma, ${ }^{2}$ and review articles on the effects of exercise on intraocular pressure have described that dynamic exercise is effective for reducing intraocular pressure. ${ }^{5,18,19}$ Glaucoma is a neurodegenerative disease characterized by progressive loss of retinal ganglion cells and their axons. ${ }^{2}$ Oxidative stress is involved in the loss of retinal ganglion cells, ${ }^{20}$ and exercise training has been found to be associated with decreased oxidative stress and increased antioxidant levels. ${ }^{21}$ In animal studies, regular exercise has been reported to reduce oxidative stress and attenuate the decreased retinal thickness and number of cells in the ganglion cell layer through aging. ${ }^{22}$ In addition, exercise can increase the level of brain-derived neurotrophic factor, which is vital for neurogenesis and dendritic growth. ${ }^{23}$ Brain-derived neurotrophic factor supplementation delays the loss of retinal ganglion cells in animal models. ${ }^{24}$ In mice, exercise after retinal damage due to elevated intraocular pressure has been reported to protect neuronal function and prevent complement-mediated elimination of synapses by maintaining the level of retinal brain-derived neurotrophic factor. ${ }^{25}$

In this study, we found a significant dose-response relationship between vertical jump and whole-body reaction time and the incidence of glaucoma. Muscle power ${ }^{26}$ and reaction time ${ }^{27}$ can be improved through exercise training. One possible explanation is that the association of vertical jump and whole-body reaction time with incidence of glaucoma could be detected because the performance levels in these tests were improved as a result of regular exercise training. ${ }^{26,27}$ It is also possible that the central and peripheral nervous systems play a partial role. ${ }^{28}$ Both muscle power and whole-body reaction time are physical fitness indices including nervous system-related components, such as contraction velocity and motor unit for the former and motor speed, neural activity, and perception of sensation for the latter. Reaction time is also related to cognitive ability. ${ }^{29}$ Neurodegeneration in glaucoma patients is similar to that found in other neurodegenerative diseases 
of the central nervous system, such as Alzheimer's disease and Parkinson's disease, ${ }^{30}$ and a thinner retinal nerve fiber layer is associated with an increased risk of developing dementia. ${ }^{31} \mathrm{~A}$ previous study examining the relationship between reaction time and glaucoma indicated that reaction time for motion detection in glaucomatous eyes was more prolonged than that in control eyes. ${ }^{32}$ It has also been reported that patients with glaucoma exhibited prolonged reaction time to a low-contrast stimulus during simulated driving and that retinal nerve fiber layer thickness loss was associated with prolonged reaction time. ${ }^{33}$ Furthermore, numerous studies have demonstrated that glaucoma may be associated with the risk of motor vehicle collisions. ${ }^{34}$ In this study, the relationship between vertical jump or whole-body reaction time and the incidence of glaucoma may also have an implication for the prevention of traffic accidents as the findings may help to elucidate glaucomarelated causative factors other than visual impairment. As a result of this study, no clear association was found between grip strength, a major index of muscle strength among various physical fitness elements, and glaucoma incidence. To our knowledge, no epidemiological studies have examined the association between muscle strength and the development of glaucoma. Meanwhile, there is no consensus on the effect of resistance exercise on intraocular pressure. ${ }^{5}$ However, some studies reported that intraocular pressure temporarily increased during resistance exercise such as weightlifting and isometric exercise. ${ }^{35,36}$ It is possible that the relationship with glaucoma may differ depending on the movement form (ie, physical fitness element), and further research is needed to examine the association between various physical fitness elements and glaucoma incidence. With regard to the balance ability, patients with glaucoma have been reported to suffer from poor postural control $^{37}$ and to be at a higher risk of falls than normal individuals. ${ }^{38}$ Vision plays a major role in maintaining postural stability. ${ }^{39}$ Results of sway performance tests with eyes closed have been reported to show no difference between glaucomatous patients and normal individuals..$^{40}$ Static balance, which was measured by one-leg standing with eyes closed, was used in this study. A confirmatory study needs to be performed to determine whether the same result can be obtained with the balance measured with visual information with eyes open.

\section{Strengths and Limitations}

The main strengths of this study are as follows. The study was a large-scale prospective cohort study of 27,051 participants with a median follow-up of 5.8 years, and we used various physical fitness parameters that objectively assessed MPF. To our knowledge, this is the first study of the relationships between the incidence of glaucoma and various physical fitness elements other than cardiorespiratory fitness. However, there were several limitations in the present study. First, recall and misclassification bias might have occurred because development of glaucoma was defined based on self-reported medical history alone. Second, although there are several different types of glaucoma, we could not examine them separately as we did not have the data required to classify glaucoma types. In addition, we did not measure the baseline intraocular pressure values and, hence, the intraocular pressure differences could not be adjusted in this study. Most individuals with glaucoma in this study may have developed primary open-angle glaucoma because primary open-angle glaucoma is the most common type of glaucoma in the world, including in Japan. ${ }^{41}$ According to a population-based prevalence survey of glaucoma among individuals aged $\geq 40$ years in Japan, the estimated prevalence of primary open-angle glaucoma was $3.9 \%$, of which $92 \%$ had intraocular pressure of $\leq 21 \mathrm{~mm} \mathrm{Hg.}{ }^{42}$ Conversely, it has been reported that the estimated prevalence of primary angle-closure glaucoma was $0.6 \%$ and the prevalence of secondary glaucoma was $0.5 \% .43$ Third, although we used MPF composed of various physical fitness elements to examine its association with the incidence of glaucoma, cardiorespiratory fitness data were not available and, therefore, could not be included in the analysis. In addition, as whole-body reaction time to visual cognition of a light stimulus was used in this study, we took visual acuity and corrections into account in the analysis. However, additional studies are required to confirm that reproducible results could be obtained with whole-body reaction time to other sensory stimuli, such as auditory sensation. Fourth, as the participants in this study were the individuals who attended annual health examinations rather than individuals randomly selected from the population, there are sample representativeness issues. In addition, a large number did not undergo all 5 physical fitness tests at baseline. However, similar results were shown after multiple imputation of missing exposure and covariate data. Although all participants in this study were Japanese, our findings are consistent with the results of previous studies investigating the relationship between cardiorespiratory fitness and incidence of glaucoma in other ethnicities. ${ }^{3,6}$ Finally, we cannot completely exclude reverse causation in this observational study, although sensitivity analysis showed similar results after excluding participants who developed glaucoma during the initial 2-year follow-up.

\section{Conclusion}

This prospective cohort study suggests that higher MPF may be associated with lower incidence of glaucoma in Japanese men and women.

\section{Acknowledgments}

The authors thank the staff of the Niigata Association of Occupational Health for their assistance with data collection as well as the study participants. We also thank Benjamin Howe for invaluable advice. This study does not have any funding source. The authors report no competing interests.

\section{References}

1. Tham YC, Li X, Wong TY, Quigley HA, Aung T, Cheng CY. Global prevalence of glaucoma and projections of glaucoma burden through 2040: a systematic review and meta-analysis. Ophthalmology. 2014; 121(11):2081-2090. PubMed ID: 24974815 doi:10.1016/j.ophtha. 2014.05.013

2. Weinreb RN, Aung T, Medeiros FA. The pathophysiology and treatment of glaucoma: a review. JAMA. 2014;311(18):1901-1911. PubMed ID: 24825645 doi:10.1001/jama.2014.3192

3. Meier NF, Lee DC, Sui X, Blair SN. Physical activity, cardiorespiratory fitness, and incident glaucoma. Med Sci Sports Exerc. 2018; 50(11):2253-2258. PubMed ID: 29985830 doi:10.1249/MSS.00000 00000001692

4. Perez CI, Singh K, Lin S. Relationship of lifestyle, exercise, and nutrition with glaucoma. Curr Opin Ophthalmol. 2019;30(2):82-88. PubMed ID: 30562241 doi:10.1097/ICU.0000000000000553

5. Zhu MM, Lai JSM, Choy BNK, et al. Physical exercise and glaucoma: a review on the roles of physical exercise on intraocular 
pressure control, ocular blood flow regulation, neuroprotection and glaucoma-related mental health. Acta Ophthalmol. 2018;96(6):e676e691. PubMed ID: 29338126 doi:10.1111/aos.13661

6. Williams PT. Relationship of incident glaucoma versus physical activity and fitness in male runners. Med Sci Sports Exerc. 2009; 41(8):1566-1572. PubMed ID: 19568204 doi:10.1249/MSS.0b013e $31819 \mathrm{e} 420 \mathrm{f}$

7. Ross R, Blair SN, Arena R, et al. Importance of assessing cardiorespiratory fitness in clinical practice: a case for fitness as a clinical vital sign: a scientific statement from the American Heart Association. Circulation. 2016;134(24):e653-e699. PubMed ID: 27881567 doi:10.1161/CIR.0000000000000461

8. Corbin CB, Pangrazi RP, Franks BD. Definitions: health, fitness, and physical activity. Pres Counc Phys Fit Sports Res Dig. 2000; 3(9):1-11.

9. Heianza Y, Kato K, Kodama S, et al. Stability and changes in metabolically healthy overweight or obesity and risk of future diabetes: Niigata wellness study. Obesity. 2014;22(11):2420-2425. PubMed ID: 25131796 doi:10.1002/oby.20855

10. Momma H, Sawada SS, Kato K, et al. Physical fitness tests and type 2 diabetes among Japanese: a longitudinal study from the Niigata Wellness Study. J Epidemiol. 2019;29(4):139-146. PubMed ID: 30058613 doi:10.2188/jea.JE20170280

11. Marques A, Santos R, Ekelund U, Sardinha LB. Association between physical activity, sedentary time, and healthy fitness in youth. Med Sci Sports Exerc. 2015;47(3):575-580. PubMed ID: 24977696 doi:10. 1249/MSS.0000000000000426

12. Rexen CT, Ersbøll AK, Møller NC, Klakk H, Wedderkopp N, Andersen LB. Effects of extra school-based physical education on overall physical fitness development-the CHAMPS study DK. Scand J Med Sci Sports. 2015;25(5):706-715. PubMed ID: 25048668 doi:10.1111/sms.12293

13. Sawada SS, Lee IM, Naito H, Tsukamoto K, Muto T, Blair SN. Muscular and performance fitness and the incidence of type 2 diabetes: prospective study of Japanese men. J Phys Act Health. 2010;7(5):627632. PubMed ID: 20864758 doi:10.1123/jpah.7.5.627

14. Marcus MW, de Vries MM, Junoy Montolio FG, Jansonius NM. Myopia as a risk factor for open-angle glaucoma: a systematic review and meta-analysis. Ophthalmology. 2011;118(10):1989-1994.e2. PubMed ID: 21684603 doi:10.1016/j.ophtha.2011.03.012

15. Cooper R, Strand BH, Hardy R, Patel KV, Kuh D. Physical capability in mid-life and survival over 13 years of follow-up: British birth cohort study. BMJ. 2014;348:g2219. PubMed ID: 24787359 doi:10. 1136/bmj.g2219

16. Li K, Hüsing A, Kaaks R. Lifestyle risk factors and residual life expectancy at age 40: a German cohort study. BMC Med. 2014; 12(1):59. PubMed ID: 24708705 doi:10.1186/1741-7015-12-59

17. Noda $\mathrm{H}$, Iso $\mathrm{H}$, Toyoshima $\mathrm{H}$, et al. Walking and sports participation and mortality from coronary heart disease and stroke. J Am Coll Cardiol. 2005;46(9):1761-1767. PubMed ID: 16256882 doi:10. 1016/j.jacc.2005.07.038

18. Risner D, Ehrlich R, Kheradiya NS, Siesky B, McCranor L, Harris A. Effects of exercise on intraocular pressure and ocular blood flow: a review. J Glaucoma. 2009;18(6):429-436. PubMed ID: 19680049 doi:10.1097/IJG.0b013e31818fa5f3

19. Gale J, Wells AP, Wilson G. Effects of exercise on ocular physiology and disease. Surv Ophthalmol. 2009;54(3):349-355. PubMed ID: 19422963 doi:10.1016/j.survophthal.2009.02.005

20. Tezel G. Oxidative stress in glaucomatous neurodegeneration: mechanisms and consequences. Prog Retin Eye Res. 2006;25(5): 490-513. PubMed ID: 16962364 doi:10.1016/j.preteyeres.2006. 07.003
21. de Sousa CV, Sales MM, Rosa TS, Lewis JE, de Andrade RV, Simões HG. The antioxidant effect of exercise: a systematic review and metaanalysis. Sports Med. 2017;47(2):277-293. PubMed ID: 27260682 doi:10.1007/s40279-016-0566-1

22. Kim CS, Park S, Chun Y, Song W, Kim HJ, Kim J. Treadmill exercise attenuates retinal oxidative stress in naturally-aged mice: an immunohistochemical study. Int J Mol Sci. 2015;16(9):21008-21020. PubMed ID: 26404251 doi:10.3390/ijms160921008

23. Szuhany KL, Bugatti M, Otto MW. A meta-analytic review of the effects of exercise on brain-derived neurotrophic factor. $J$ Psychiatr Res. 2015;60:56-64. PubMed ID: 25455510 doi:10.1016/j. jpsychires.2014.10.003

24. Mysona BA, Zhao J, Bollinger KE. Role of BDNF/TrkB pathway in the visual system: therapeutic implications for glaucoma. Expert Rev Ophthalmol. 2017;12(1):69-81. PubMed ID: 28751923 doi:10.1080/ 17469899.2017.1259566

25. Chrysostomou V, Galic S, van Wijngaarden P, Trounce IA, Steinberg GR, Crowston JG. Exercise reverses age-related vulnerability of the retina to injury by preventing complement-mediated synapse elimination via a BDNF-dependent pathway. Aging Cell. 2016;15(6):10821091. PubMed ID: 27613664 doi:10.1111/acel.12512

26. Straight CR, Lindheimer JB, Brady AO, Dishman RK, Evans EM. Effects of resistance training on lower-extremity muscle power in middle-aged and older adults: a systematic review and meta-analysis of randomized controlled trials. Sports Med. 2016;46(3):353-364. PubMed ID: 26545362 doi:10.1007/s40279-015-0418-4

27. Fernandes RM, Correa MG, Dos Santos MAR, et al. The effects of moderate physical exercise on adult cognition: a systematic review. Front Physiol. 2018;9:667. PubMed ID: 29937732 doi:10.3389/ fphys.2018.00667

28. Liu M, Duggan J, Salt TE, Cordeiro MF. Dendritic changes in visual pathways in glaucoma and other neurodegenerative conditions. Exp Eye Res. 2011;92(4):244-250. PubMed ID: 21310146 doi:10.1016/j. exer.2011.01.014

29. Deary IJ, Johnson W, Starr JM. Are processing speed tasks biomarkers of cognitive aging? Psychol Aging. 2010;25(1):219-228. PubMed ID: 20230141 doi:10.1037/a0017750

30. Ramirez AI, de Hoz R, Salobrar-Garcia E, et al. The role of microglia in retinal neurodegeneration: Alzheimer's disease, Parkinson, and glaucoma. Front Aging Neurosci. 2017;9:214. PubMed ID: 28729832 doi:10.3389/fnagi.2017.00214

31. Mutlu U, Colijn JM, Ikram MA, et al. Association of retinal neurodegeneration on optical coherence tomography with dementia: a population-based study. JAMA Neurol. 2018;75(10):1256-1263. PubMed ID: 29946702 doi:10.1001/jamaneurol.2018.1563

32. Westcott MC, Fitzke FW, Viswanathan AC, Hitchings RA. Response time prolongation for a motion stimulus in patients with glaucoma and its relationship with elevation of the motion threshold. J Glaucoma. 2000;9(4):289-295. PubMed ID: 10958601 doi:10.1097/ 00061198-200008000-00002

33. Tatham AJ, Boer ER, Rosen PN, et al. Glaucomatous retinal nerve fiber layer thickness loss is associated with slower reaction times under a divided attention task. Am J Ophthalmol. 2014; 158(5):1008-1017.e2. PubMed ID: 25068641 doi:10.1016/j.ajo. 2014.07.028

34. Montana CL, Bhorade AM. Glaucoma and quality of life: fall and driving risk. Curr Opin Ophthalmol. 2018;29(2):135-140. PubMed ID: 29266021 doi:10.1097/ICU.0000000000000455

35. Vieira GM, Oliveira HB, de Andrade DT, Bottaro M, Ritch R. Intraocular pressure variation during weight lifting. Arch Ophthalmol. 2006;124(9):1251-1254. PubMed ID: 16966619 doi:10.1001/ archopht.124.9.1251 
36. Bakke EF, Hisdal J, Semb SO. Intraocular pressure increases in parallel with systemic blood pressure during isometric exercise. Invest Ophthalmol Vis Sci. 2009;50(2):760-764. PubMed ID: 18836162 doi:10.1167/iovs.08-2508

37. Diniz-Filho A, Boer ER, Gracitelli CP, et al. Evaluation of postural control in patients with glaucoma using a virtual reality environment. Ophthalmology. 2015;122(6):1131-1138. PubMed ID: 25892017 doi:10.1016/j.ophtha.2015.02.010

38. Haymes SA, Leblanc RP, Nicolela MT, Chiasson LA, Chauhan BC. Risk of falls and motor vehicle collisions in glaucoma. Invest Ophthalmol Vis Sci. 2007;48(3):1149-1155. PubMed ID: 17325158 doi:10. 1167/iovs.06-0886

39. Wade MG, Jones G. The role of vision and spatial orientation in the maintenance of posture. Phys Ther. 1997;77(6):619-628. PubMed ID: 9184687 doi:10.1093/ptj/77.6.619
40. Shabana N, Cornilleau-Pérès V, Droulez J, Goh JC, Lee GS, Chew PT. Postural stability in primary open angle glaucoma. Clin Exp Ophthalmol. 2005;33(3):264-273. PubMed ID: 15932530 doi:10. 1111/j.1442-9071.2005.01003.x

41. Quigley HA, Broman AT. The number of people with glaucoma worldwide in 2010 and 2020. Br J Ophthalmol. 2006;90(3):262-267. PubMed ID: 16488940 doi:10.1136/bjo.2005.081224

42. Iwase A, Suzuki Y, Araie M, et al. The prevalence of primary open-angle glaucoma in Japanese: the Tajimi Study. Ophthalmology. 2004; 111(9):1641-1648. PubMed ID: 15350316 doi:10.1016/j.ophtha.2004. 03.029

43. Yamamoto T, Iwase A, Araie M, et al. The Tajimi Study report 2: prevalence of primary angle closure and secondary glaucoma in a Japanese population. Ophthalmology. 2005;112(10):1661-1669. PubMed ID: 16111758 doi:10.1016/j.ophtha.2005.05.012 